Human Ethology Bulletin 33(3) - Special Issue to commemorate the life of Irenäus Eibl-Eibesfeldt (2018): 3-4

\title{
EIbL-EIBESFELDT: PATHFINDER AND FATHER OF HUMAN ETHOLOGY
}

\section{Peter LaFreniere}

Professor Emeritus, Department of Psychology, University of Main

peter@bluehillbaygallery.com

Irenäus Eibl-Eibesfeldt (hereafter, Eibl) was essentially a pathfinder, leading the way in a new direction and pursuing the path forward wherever it led. Like his mentor and guide, Konrad Lorenz, Eibl brought a fresh, vital perspective during an age where biological thinking was mostly overlooked by social scientists. But thanks to Eibl, self-labeled human ethologists began to have an impact over the 2 nd half of the 20th century.

Eibl visited Bill Charlesworth at the University of Minnesota in 1965 and was an immediate hit with students and faculty. A few years later a small band of human ethologists held their first international meeting in Minnesota, followed up by meetings in Starnberg (Eibl's first research station); and then in London under the sponsorship of Nick BlurtonJones. By 1972 ISHE was on its way and suddenly there was a burst of 
exciting empirical publications consisting largely of direct observation of human social interaction.

These early observational studies by German, Austrian, British, American and Canadian ethologists energized diverse disciplines, none more so than developmental psychology, at just the time I entered the field. Eibl was one of several key figures in the inception of ISHE and its first President. I had occasion to get to know Eibl, through his close friend, Bill Charlesworth, who was my own mentor at Minnesota in the late 1970's.

Much later, as HEB editor, I was fortunate to visit Eibl at his home in Socking and interview him over several days at his research lab in Andechs. Having just reread the interview, I find Eibl's ideas as fresh and relevant as the day I recorded them in the spring of 2000. Here's just one tidbit from Eibl during the interview: "We have to face the fact that presidents with stone-age mentalities are now guiding superpowers, with all their bleeding hearts and girlfriends".

I hope that statement from 2000 entices you to read the full interview republished here. You will hear Eibl's comments on his early experiences in post-war Vienna and his early days as a research associate with Lorenz in the Max-Planck Society, and significant insights from imprinting to indoctrination covering a remarkable 70-year history of ethological inquiry.

All of us who knew him will miss his benevolent grandfatherly presence in ISHE.

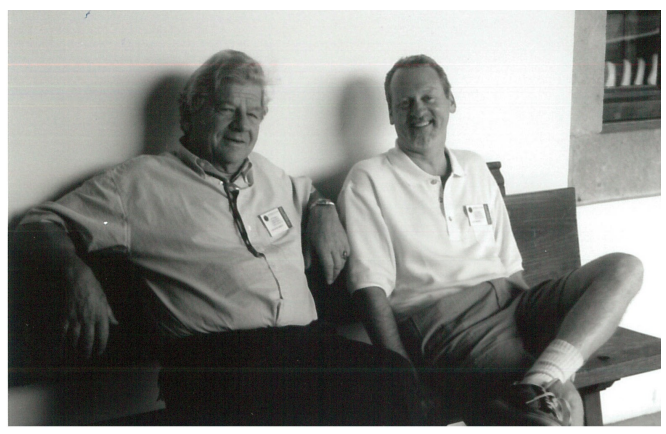

Eibl and Peter LaFreniere, Salamanca, 2001 (Photo credit: Bill Charlesworth) 